\title{
Permeabilidade de concretos refratários multifuncionais
}

\section{(Permeability of multifunctional refractory castables)}

\author{
M. D. M. Innocentini, A. R. Studart, R. G. Pileggi, V. C. Pandolfelli \\ Departamento de Engenharia de Materiais \\ Universidade Federal de S. Carlos -UFSCar \\ Rod. Washington Luiz, km 235, S. Carlos, SP, 13565-905 \\ pmmi@iris.ufscar.brouvicpando@power.ufscar.br
}

\section{Resumo}

Concretos multifuncionais oferecem como principal vantagem a possibilidade de aplicação do material refratário através de diversas técnicas de instalação (p.e. socagem, vibração, projeção, auto-escoamento) variando-se apenas o teor de água. Essa versatilidade durante a etapa de aplicação associada à necessidade de redução do estoque de materiais refratários nas indústrias siderúrgicas têm resultado em uma crescente demanda por concretos multifuncionais. No entanto, cabe avaliar se a versatilidade desse tipo de concreto durante a aplicação também é observada em etapas posteriores à instalação, particularmente nos processos de secagem e aquecimento do revestimento refratário. A permeabilidade é uma das principais características que influenciam a velocidade de secagem dos concretos e a possibilidade de explosão do revestimento durante o aquecimento. O objetivo deste trabalho foi comparar a permeabilidade de concretos refratários multifuncionais com composições normalmente aplicadas com técnicas específicas de instalação. Os resultados indicam que a distribuição granulométrica e o teor de água adicionada são os principais fatores determinantes da permeabilidade de concretos de alta alumina com ultra-baixo teor de cimento.

Palavras-chave: concreto refratário, multifuncional, alumina, permeabilidade, secagem.

\section{INTRODUÇÃO}

O desenvolvimento de concretos refratários tem possibilitado a otimização da etapa de aplicação do revestimento de equipamentos siderúrgicos. Ao contrário dos tijolos convencionais, que oferecem poucas alternativas quanto a essa etapa, os concretos refratários podem ser aplicados por diversos métodos, incluindo a socagem, vibração, auto-escoamento, bombeamento, projeção, entre outros. A utilização dessas técnicas tem possibilitado a automação da etapa de instalação do refratário e uma significativa redução do tempo de parada dos equipamentos, resultando em consideráveis ganhos de produtividade ao usuário.

A seleção da técnica mais adequada de aplicação normalmente

\begin{abstract}
The main advantage of multifunctional castables is their ability of being applied using different installation techniques (i.e., ramming, vibration, gunning, self-flowing, etc.). Such versatility during the placing procedure associated to the necessity of reducing the amount of spare refractory material in the steel-making industries have resulted in an increasing demand for multifunctional castables. However, it is important to evaluate whether the benefits of these castables during installation are also observed after the start-up of equipment, particularly along the drying and heating processes of the refractory lining. Permeability is one of the main properties that influences the drying rate and the susceptibility of castables to explosion during heating. The objective of this paper is to compare the permeability of multifunctional refractory castables with that of compositions usually applied through specific installation techniques. Results indicate that the particle size distribution and the water content are the key factors that determine the permeability of high-alumina ultra-lowcement castables.
\end{abstract}

Keywords: refractory castable, multifunctional, alumina, permeability, drying.

envolve diversos fatores, como a disponibilidade de equipamentos e de mão-de-obra especializada, custo, moldes, facilidade de acesso à região a ser revestida, entre outros. Isso exige que os usuários de materiais refratários mantenham estoques para cada categoria de concreto (socados, vibrados, auto-escoantes, etc.), muitas vezes com similares características químicas. Além de implicar em custos adicionais ao usuário, $\mathrm{o}$ armazenamento acentua a possibilidade de vencimento do prazo de validade dos concretos.

Em virtude disso, têm-se observado recentemente uma significativa demanda por concretos, denominados multifuncionais, que possam ser aplicados através de diferentes técnicas, dependendo apenas do teor de água adicionado à composição [1]. Estudos anteriores indicam que a distribuição de tamanho de partículas parece 
ser o principal fator determinante do caráter multifuncional dos concretos, afetando diretamente suas características durante a mistura, seu comportamento reológico e desempenho a altas temperaturas [2].

A permeabilidade é outra propriedade dos concretos que tem despertado bastante interesse na área de cerâmicas refratárias, em decorrência principalmente da sua influência direta sobre a velocidade de secagem e sobre a taxa de aquecimento máxima permitida ao revestimento refratário. Tais características determinam o tempo necessário para a retomada da operação dos equipamentos e, por isso, são fatores decisivos durante a seleção do material refratário. Além disso, a permeabilidade dos concretos após a queima afeta diretamente a susceptibilidade do refratário a processos de corrosão e ataque químico que podem comprometer seu desempenho a alta temperatura.

Desta forma, o objetivo do presente trabalho foi comparar a permeabilidade e a taxa de secagem de concretos multifuncionais preparados com e sem vibração durante a moldagem. A distribuição de tamanho de partículas e o teor de água adicionada na mistura foram as principais variáveis avaliadas no estudo, em virtude da sua influência significativa sobre as características de aplicação do concreto [2].

\section{MATERIAIS E MÉTODOS}

Concretos com distribuições de tamanho de partículas distintas foram preparados baseado no modelo de empacotamento de Andreasen, utilizando valores do coeficiente de distribuição q iguais a 0,21, 0,26 e 0,31, conforme indicado na Fig. 1 .

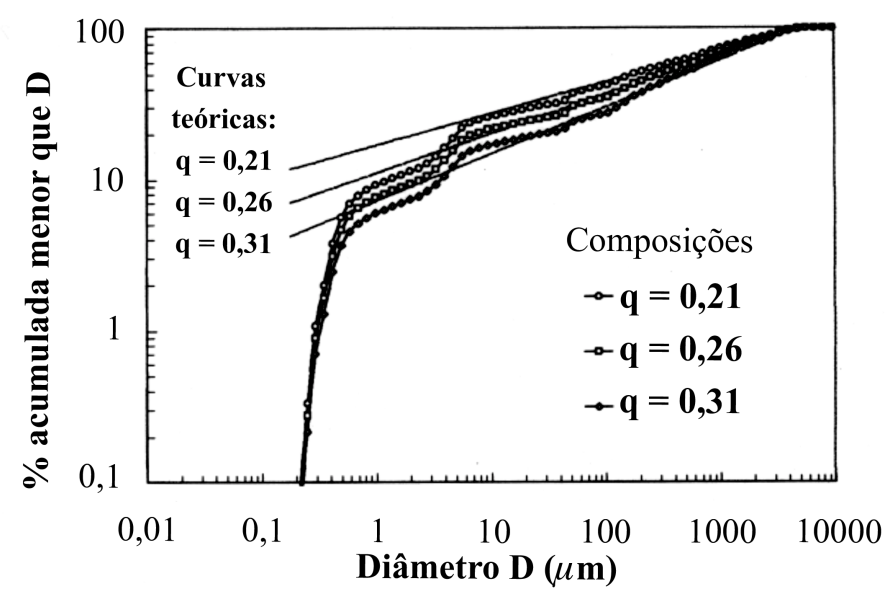

Figura 1: Distribuição de tamanho de partículas dos concretos avaliados.

[Figure 1: Particle size distribution of refractory castables prepared in this work].

As composições foram preparadas com alumina eletrofundida branca (malhas 4/10 a-200) como agregados (75,2 a 82,6\%-peso). Aluminas calcinadas (16,4 a 23,8\%-peso) e cimento de aluminato de cálcio (1\%-peso) foram utilizadas como constituintes da matriz. Ácido cítrico $\left(0,36 \mathrm{mg} / \mathrm{m}^{2}\right)$ foi adicionado aos concretos como dispersante das partículas finas. A formulação completa das composições avaliadas e o procedimento de mistura utilizado para a preparação dos concretos podem ser encontrados na referência [2].

Corpos de prova cilíndricos com $7,5 \mathrm{~cm}$ de diâmetro e $2,5 \mathrm{~cm}$ de altura foram produzidos através da moldagem dos concretos misturados. Trabalhos anteriores mostraram que a técnica de apli- cação (moldagem) mais adequada para cada composição depende da distribuição granulométrica do concreto e do teor de água adicionada [2]. No entanto, a maior parte das amostras neste trabalho foi submetida à vibração durante a preparação com o objetivo de se avaliar o efeito do coeficiente q de distribuição granulométrica e do teor de água. $\mathrm{O}$ efeito da condição de moldagem sobre a permeabilidade dos concretos foi avaliado produzindo-se composições com $q=0,26$ e $16 \%$ em volume de água, com e sem vibração. A cura das composições foi efetuada à temperatura de $40^{\circ} \mathrm{C} \mathrm{e}$ teor de umidade de $98 \%$, por um período de no mínimo 24 horas.

Em seguida, as amostras foram submetidas à secagem em estufa a $100{ }^{\circ} \mathrm{C}$ até a total eliminação da água livre dos concretos. $\mathrm{O}$ acompanhamento da perda de massa dos corpos $( \pm 0,01 \mathrm{~g})$ com o tempo possibilitou a determinação da curva de secagem dos concretos.

Os ensaios de permeabilidade ao ar dos concretos foram efetuados à temperatura ambiente $\left(\sim 25^{\circ} \mathrm{C}\right)$, em equipamento esquematizado na Fig. 2 conforme método detalhado em [3]. Duas amostras de cada composição foram usadas como forma de verificar a reprodutibilidade da composição analisada quanto à permeabilidade.

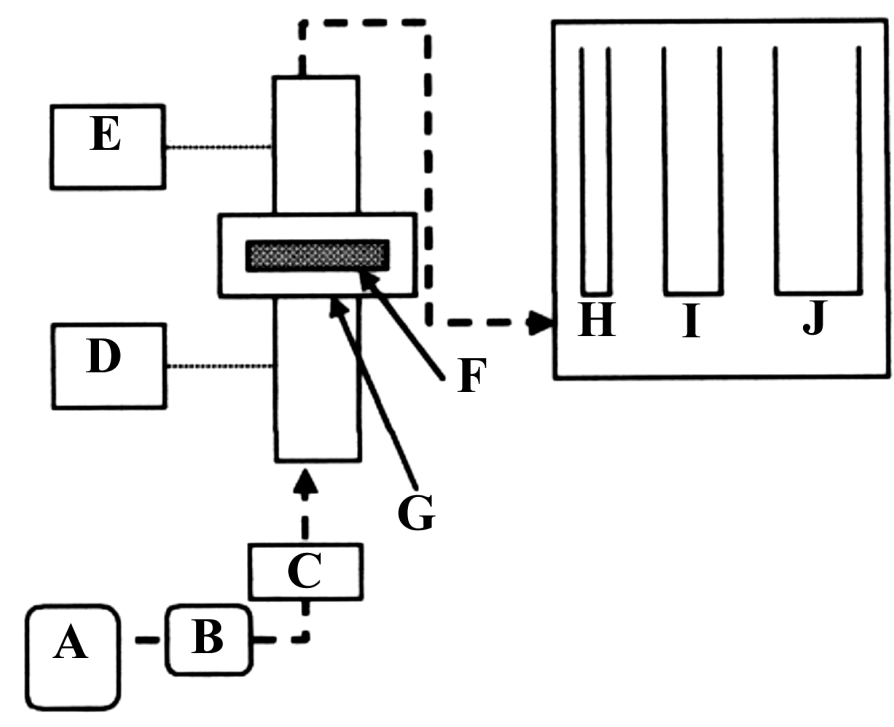

A - Compressor de ar, $2 \mathrm{Hp}$

B - Filtro para óleo e umidade

C - Válvula de controle de pressão

$\mathrm{D}$ - Transdutor e leitor de pressão, $\mathrm{P}=0$ a $10 \mathrm{bar}$

E - Manômetro, $\Delta \mathrm{P}=0$ a $500 \mathrm{mmH}_{2} \mathrm{O}$

$\mathrm{F}$ - Amostra cilíndrica $(\mathrm{d}=7.5 \mathrm{~cm}, \mathrm{~L}=2.5 \mathrm{~cm})$

$\mathrm{G}$ - Porta-amostras (diâmetro útil $=5.7 \mathrm{~cm}$ )

$\mathrm{H}$ - Bolhômetro, $\mathrm{Q}=0.7$ a $36 \mathrm{~mL} / \mathrm{min}$

I - Bolhômetro, $\mathrm{Q}=60$ a $600 \mathrm{~mL} / \mathrm{min}$

J - Bolhômetro, $\mathrm{Q}=0.5$ a $14 \mathrm{~L} / \mathrm{min}$

Figura 2: Detalhes esquemáticos do aparato usado neste trabalho para medição da permeabilidade de concretos refratários.

[Figure 2: Schematic details of permeameter used in this work].

Os dados experimentais foram ajustados segundo a equação de Forchheimer para fluidos compressíveis [3-5]:

$$
\frac{\mathrm{Pe}^{2}-\mathrm{Ps}^{2}}{2 \mathrm{P}_{\mathrm{s}} \mathrm{L}}=\frac{\mu \mathrm{v}_{s}}{\mathrm{k}_{1}}+\frac{\rho \mathrm{v}_{\mathrm{s}}^{2}}{\mathrm{k}_{2}}
$$


na qual $\mathrm{P}_{\mathrm{e}}$ e $\mathrm{P}_{\mathrm{s}}$ são respectivamente as pressões absolutas na entrada e na saída da amostra, $\rho$ e $\mu$ são respectivamente a densidade e a viscosidade do ar, $\mathrm{v}_{\mathrm{s}}$ é a velocidade superficial do ar, calculada pela divisão da vazão volumétrica $(\mathrm{Q})$ pela área frontal e livre para escoamento (1). Os parâmetros $\mathrm{k}_{1}$ e $\mathrm{k}_{2}$ são constantes conhecidos respectivamente como permeabilidades Darciana e não-Darciana.

As constantes de permeabilidade, propriedades dependentes apenas do meio poroso refratário, foram obtidas neste trabalho por ajuste dos dados experimentais de $\mathrm{v}_{\mathrm{s}}$ versus $\left[\mathrm{P}_{\mathrm{e}}{ }^{2}-\mathrm{P}_{\mathrm{s}}{ }^{2}\right] / 2 \mathrm{P}_{\mathrm{s}} \mathrm{L}$ na equação (A) através do método dos mínimos quadrados. Em cada ensaio, os valores de pressão e vazão foram coletados em tréplica para garantir a confiabilidade da curva. Considerou-se $\mu_{\mathrm{ar}=} 1,8 \times 10^{-5} \mathrm{~Pa}$.s e $\rho_{\mathrm{ar}}=1,08 \mathrm{~kg} / \mathrm{m}_{3}$ para $\mathrm{T}_{\mathrm{amb}}=25^{\circ} \mathrm{C}$ e $\mathrm{P}_{\mathrm{atm}}=\mathrm{Ps}=690 \mathrm{mmHg}$.

\section{RESULTADOS E DISCUSSÃO}

Observa-se na Fig. 3 que o aumento do teor de água causou a elevação de ambas constantes de permeabilidade, $\mathrm{k}_{1}$ e $\mathrm{k}_{2}$, porém em intensidades distintas. Enquanto $\mathrm{k}_{1}$ aumentou $91,5 \%$ para adi-
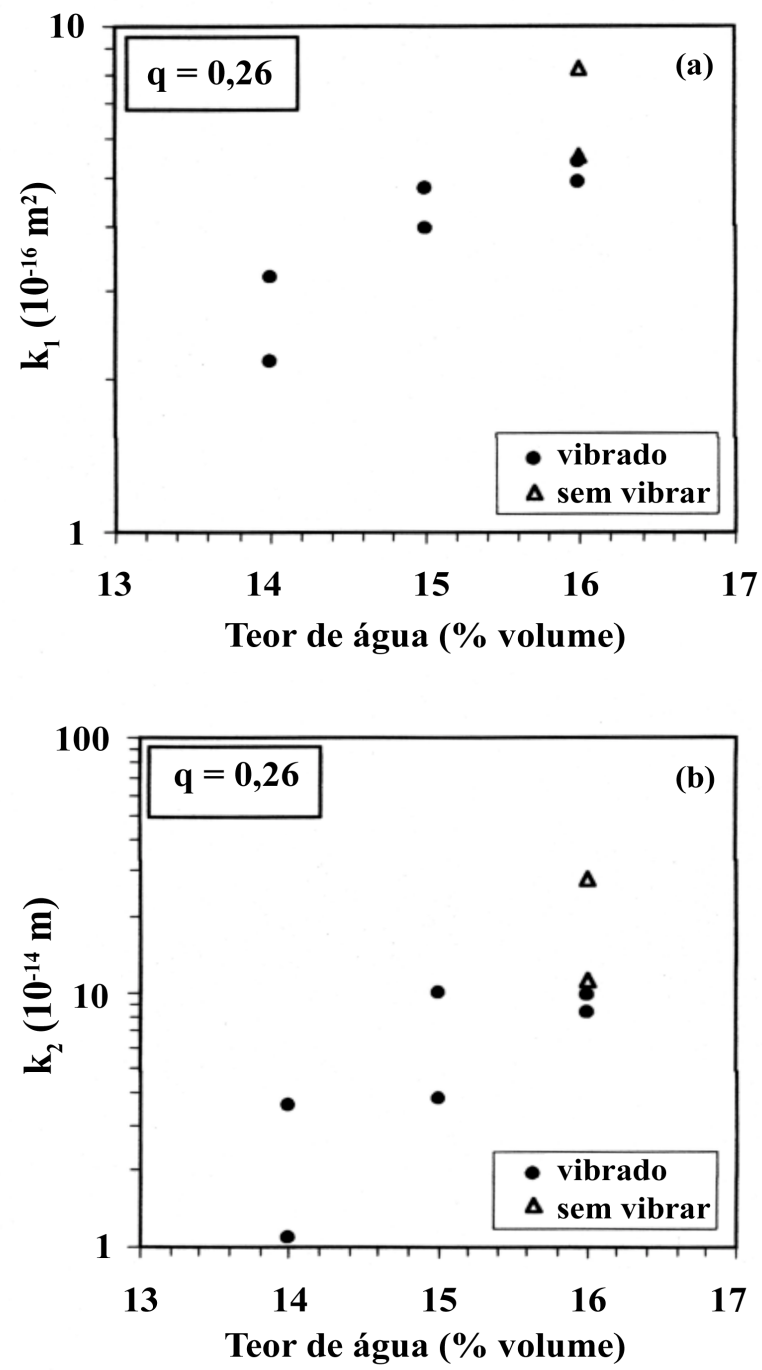

Figura s: mnuencia uo teor ue agua ue mnstura sovre as constantes ue permedoilidade para amostras com mesma distribuição granulométrica $(q=0,26)$. (a) Permeabilidade Darciana, $\mathrm{k}_{1}$. (b) Permeabilidade não-Darciana, $\mathrm{k}_{2}$.

[Figure 3: Influence of water content on the permeability of castables with same particle size distribution $(q=0.26)$. (a) Darcian permeability, $k_{l}$. (b) Non-Darcian permeability, $\left.k_{2}\right]$. ções entre $14 \%$ e $16 \%$ de água, $\mathrm{k}_{2}$ teve um aumento de 3,8 vezes no mesmo intervalo. O desvio padrão $(\sigma)$ diminuiu com o aumento do teor de água $\left(\sigma_{\mathrm{k} 1}\right.$ caiu de $27,2 \%$ para apenas $6,8 \%$ enquanto $\sigma_{\mathrm{k} 1}$ variou de $75,8 \%$ para $10,2 \%$ ) indicando que as amostras tornaramse mais homogêneas em relação à permeabilidade.

A explicação para o comportamento observado está relacionada aos poros deixados na estrutura durante a secagem. Uma vez que todas as amostras apresentaram mesma distribuição granulométrica $(q=0,26)$ e foram curadas à mesma temperatura $\left(40{ }^{\circ} \mathrm{C}\right)$, fornecendo as mesmas fases hidratadas, a quantidade de água livre removida pela secagem $\left(110^{\circ} \mathrm{C}\right)$ foi a única variável envolvida. Assim, o teor de água pode ser associado diretamente à fração de poros deixados na estrutura.

Os resultados da Fig. 3 também confirmam a idéia de que poros deixados pela secagem de água de mistura são permeáveis e, portanto, se não forem devidamente sinterizados durante o tratamento térmico, serão fonte potencial para a infiltração de metais fundidos e para a conseqüente deterioração química e mecânica do concreto refratário. Por outro lado, a maior permeabilidade dos concretos permite que durante o tratamento térmico a saída de água de hidratação também seja facilitada.

Em relação à influência da técnica de moldagem, observa-se que o concreto não-vibrado apresentou nível de permeabilidade maior $\left(\mathrm{k}_{1}=6,89 \pm 1,91 \times 10^{-16} \mathrm{~m}^{2} \mathrm{e}_{2}=19,60 \pm 11,97 \times 10^{-14} \mathrm{~m}\right)$ em relação àquele de mesmo teor de água (16\%), porém vibrado durante a conformação $\left(\mathrm{k}_{1}=5,12 \pm 0,35 \times 10^{-16} \mathrm{~m}^{2} \mathrm{e} \mathrm{k}_{2}=8,99 \pm 0,99 \times 10^{-14} \mathrm{~m}\right)$. A explicação está na melhor acomodação estrutural deste último, o que garante um melhor empacotamento e a eliminação de eventuais bolhas de ar originadas durante a mistura.

A diminuição do desvio nos valores de permeabilidade reflete a melhor homogeneização que a adição de água confere à estrutura. A obtenção de amostras mais reprodutíveis pelo aumento do teor de água não indica, contudo, a otimização da propriedade analisada, isto é, permeabilidade, uma vez que neste caso, conforme mencionado, a penetração de fluidos corrosivos vai depender também da distribuição de tamanho destes poros. A vibração do concreto durante a sua conformação garantiu uma melhor uniformidade da estrutura, tornando a permeabilidade mais reprodutível.

A Fig. 4 apresenta os resultados de permeabilidade em relação à variação na distribuição granulométrica do concreto, mantendose constante o teor de água (14 vol\%).

Observa-se nas Figs. 4-a e 4-b o aumento de ambas constantes de permeabilidade $\mathrm{k}_{1}$ e $\mathrm{k}_{2}$ com o aumento da fração de agregados na estrutura, porém com intensidade muito superior àquela observada com o aumento no teor de água. $\mathrm{O}$ parâmetro $\mathrm{k}_{1}$ subiu cerca de 6 vezes entre $q=0,21$ e $q=0,31$ enquanto $k_{2}$ apresentou aumento de 55 vezes nesse intervalo. Não houve, contudo uma tendência clara quanto ao desvio padrão observado entre os valores de permeabilidade.

A explicação para esses resultados é mais complexa e está relacionada com as diferenças entre as propriedades na matriz do concreto e aquelas na região interfacial entre matriz e agregado. Embora tenham trabalhado com concretos não-refratários e com outros teores de cimento, Scrivener e Nemati [6], propõem que a microestrutura da região interfacial seja determinada pelo empacotamento das partículas da matriz sobre a superfície dos grãos maiores (agregados). Pela ocorrência de efeitos de parede, as partículas da matriz empacotam-se com menor eficiência na interface com os agregados, formando uma região com gradiente de 

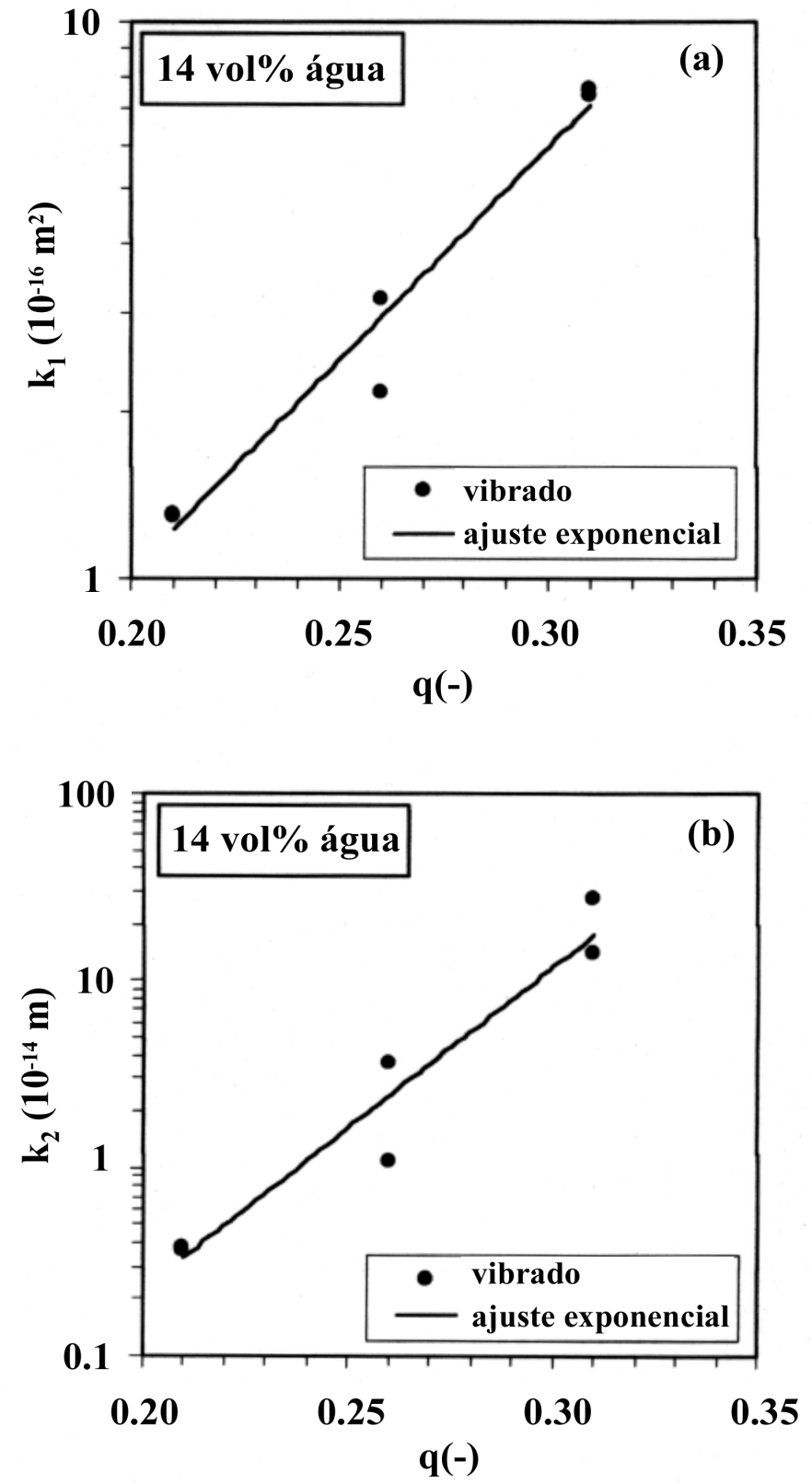

Figura 4: Influência da distribuição granulométrica sobre as constantes de permeabilidade dos concretos com teor de água constante (14 vol\%). (a) Permeabilidade Darciana, $\mathrm{k}_{1}$. (b) Permeabilidade não-Darciana, $\mathrm{k}_{2}$.

[Figure 4: Influence of particle size distribution on the permeability of castables with same water content (14 vol\%). (a) Darcian permeability, $k_{l}$. (b) Non-Darcian permeability, $\left.k_{2}\right]$.

porosidade cujo valor reduz-se a partir da interface. A extensão da zona afetada pelos efeitos de parede pode chegar, segundo o autor, à espessura equivalente ao tamanho das maiores partículas da matriz $(100 \mu \mathrm{m})$, embora o tamanho médio dos poros encontrados por eles esteja em torno de $30 \mu \mathrm{m}$. Por serem conectados, os poros nessa região tenderiam a aumentar a permeabilidade da estrutura.

Os resultados apresentados na Fig. 4 reforçam o mecanismo proposto [6]. O aumento no coeficiente de Andreasen (q) indica o aumento na quantidade relativa de agregados no concreto, causando consequentemente o aumento na densidade de regiões interfaciais matriz-agregado passíveis de ocorrência do efeito de parede. Essa fração de poros menos tortuosos e interconectados é responsável pelo aumento pronunciado observado das constantes de permeabilidade $\mathrm{k}_{1}$ e $\mathrm{k}_{2}$.
Comparando os efeitos das duas variáveis analisadas neste trabalho, constata-se que a permeabilidade nos concretos é muito mais sensível à modificação estrutural causada pela distribuição granulométrica do que pelo teor de água. Os poros gerados pelo efeito de parede são muito menos resistentes ao escoamento de fluidos do que os poros deixados pela saída de água de mistura, embora a fração total de poros em cada caso possa diferir. Em outras palavras, a morfologia dos poros afeta fortemente o comportamento das constantes de permeabilidade. Enquanto o parâmetro $\mathrm{k}_{1}$ no termo linear $\left(\mu \mathrm{v}_{\mathrm{s}} / \mathrm{k}_{1}\right)$ da equação de Forchheimer reflete a influência da área de interação sólido-fluido, o parâmetro $\mathrm{k}_{2}$ pode ser relacionado no termo parabólico $\left(\rho \mathrm{v}_{\mathrm{s}}^{2} / \mathrm{k}_{2}\right)$ com o efeito da tortuosidade do meio poroso e com a turbulência gerada pelo mesmo sobre o fluido. Os dados nas Figs. 3 e 4 permitem verificar que a razão entre as constantes $\mathrm{k}_{2} / \mathrm{k}_{1}$ aumenta 2,2 vezes quando o teor de água sobe de $14 \%$ para $16 \%$, mas aumenta quase 10 vezes quando o coeficiente de Andreasen passa de $q=0,21$ para $q=0,31$. $O$ aumento da razão $\mathrm{k}_{2} / \mathrm{k}_{1}$ mais pronunciado com o coeficiente (q) vem, deste modo, confirmar indiretamente a formação de um trajeto preferencialmente menos tortuoso para o escoamento de fluidos.

A Fig. 5 confirma que as alterações na morfologia dos poros não são seguidas necessariamente da variação na porosidade da estrutura. Para os concretos com mesma distribuição granulométrica (Fig. 5-a), é nítido o aumento na porosidade aparente de 11,9\% para $13,2 \%$ quando o teor de água foi elevado de $14 \%$ para 16 vol\%. Para concretos preparados com um mesmo teor de água, no entanto, (Fig. 5-b), a porosidade manteve-se praticamente constante em $11,9 \%$ com a variação na proporção matriz-agregado $(q=0,21$ para $q=0,31$ ). Comparando as Figs. 3, 4 e 5, fica claro então que, embora em menor quantidade, os poros originados do efeito de parede na região interfacial matriz-agregado influenciaram de forma muito mais pronunciada a permeabilidade do concreto do que os poros em maior quantidade formados na saída da água de mistura.

A Fig. 6 apresenta a influência da distribuição granulométrica e do teor de água sobre a velocidade de secagem dos concretos refratários. As curvas de perda de massa, representando a média de três corpos analisados em cada composição, foram obtidas à temperatura de $100{ }^{\circ} \mathrm{C}$. Assim, embora não seja possível analisar quantitativamente as informações sobre a cinética de secagem, a comparação entre concretos de diferentes composições pode ser realizada qualitativamente.

Na Fig. 6-a, é comparada a velocidade de secagem dos concretos com mesma distribuição granulométrica $(q=0,26)$. Nota-se que não houve diferença significativa entre as curvas para $14 \%$ e $15 \%$ de água após 500 minutos de secagem. Ambas apresentaram mesma velocidade de secagem (inclinação da curva) e praticamente a mesma perda total de água $\left(0,019 \mathrm{~g}\right.$ água $\left./ \mathrm{g}_{\text {amostra seca }}\right)$. Diferença no comportamento de secagem foi notada para amostra preparada com $16 \%$ de água, para a qual a velocidade de secagem tornou-se maior. A amostra contendo $16 \%$ de água, porém não vibrada durante a conformação, foi, no entanto, a que apresentou maior velocidade e maior perda de água em termos absolutos. A explicação para os diferentes valores finais de perda de massa é que a vibração do concreto causa um melhor empacotamento da estrutura, eliminando possíveis zonas com excesso de água. No concreto não-vibrado auto-escoante, a água aprisionada responde pela diferença observada na taxa de secagem na Fig. 6-a.

Na Fig. 6-b são analisadas as curvas de secagem dos concretos com mesmo teor de água (14\%) e diferentes distribuições 

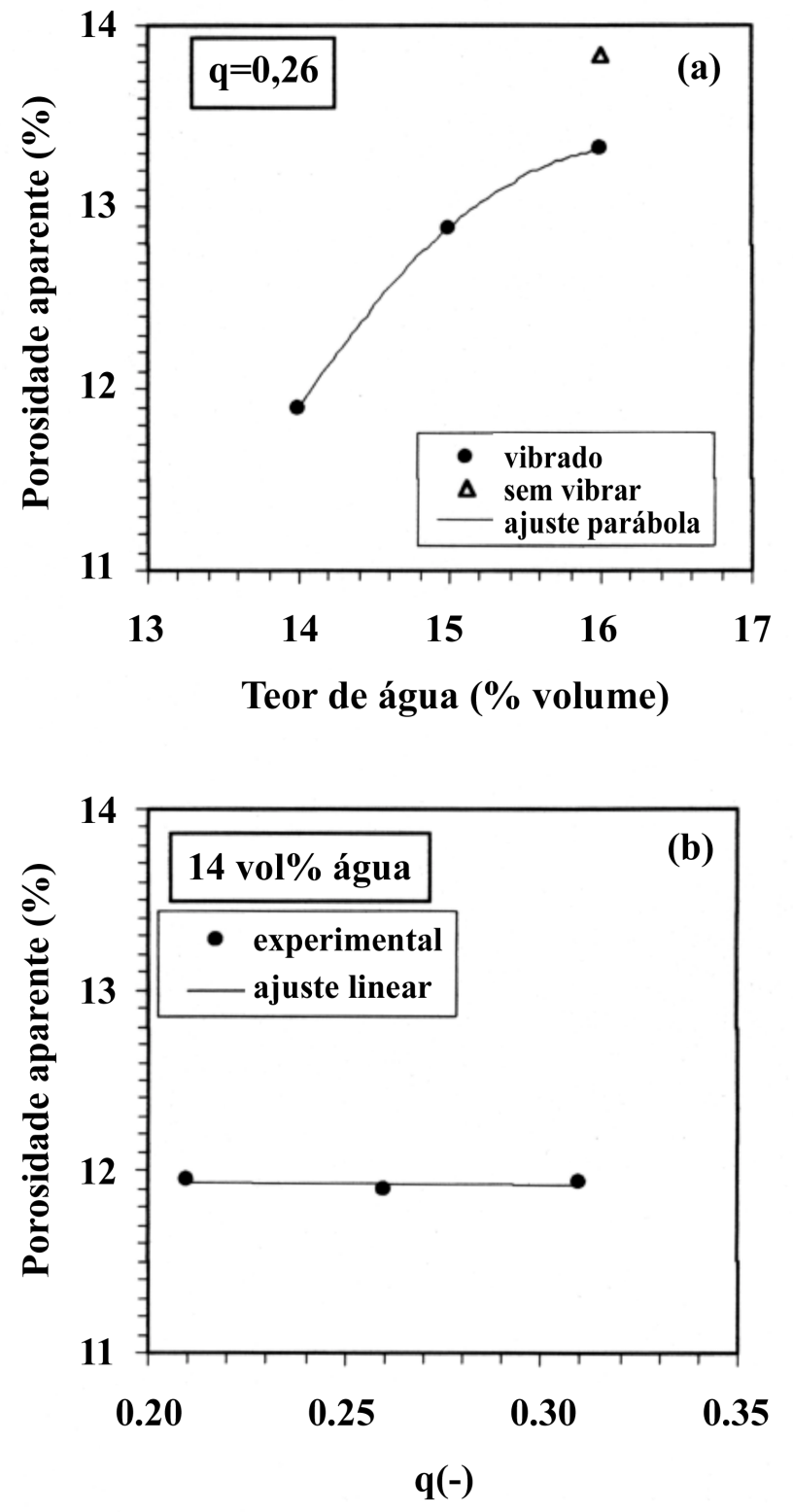

Figura 5: Variações na porosidade aparente de concretos refratários decorrentes de (a) alteração no teor de água de mistura; (b) alteração na distribuição granulométrica. [Figure 5: Variation in the apparent porosity of refractory castables due to: (a) water content variation, (b) particle size distribution variation].

granulométricas. A velocidade de secagem foi maior nos primeiros 500 minutos quanto maior o teor de agregados (maior q). A causa desse comportamento está associada à microestrutura formada em cada concreto. Conforme discutido anteriormente, a região de interface matriz-agregado é a responsável pela geração de fração de poros menos tortuosos e de maior facilidade de acesso à superfície. $\mathrm{O}$ aumento no parâmetro q de 0,21 para 0,31 causou assim o aumento da densidade dessa região interfacial, aumentando a permeabilidade e a velocidade de secagem do material.

A análise comparativa dos resultados de permeabilidade, porosidade aparente e secagem efetuada neste trabalho reforça a hipótese de que poros com diferentes morfologias são gerados com a variação da distribuição granulométrica e do teor de água, resultando em diferentes propriedades de transporte de fluidos. Houve uma associação clara entre $\mathrm{o}$ aumento de permeabilidade e a velocidade de secagem.
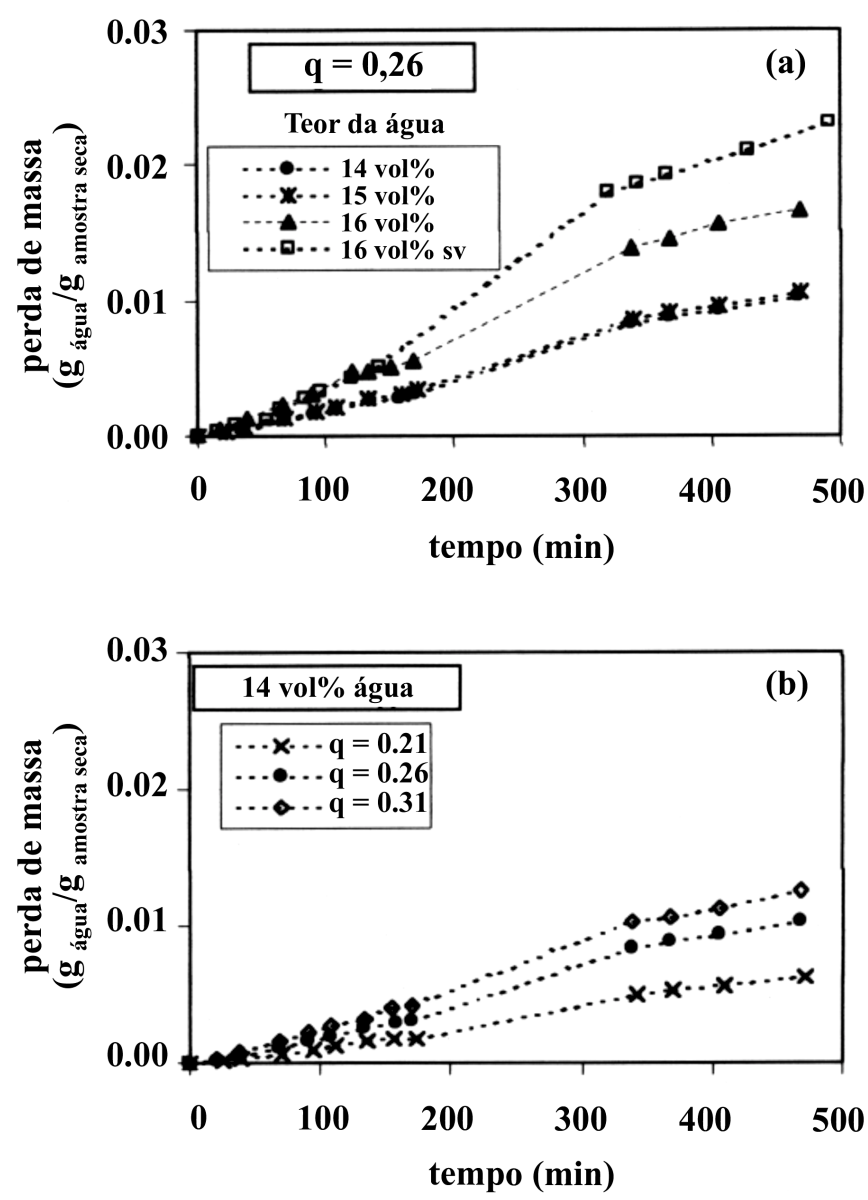

Figura 6: Influência (a) do teor de água e (b) da distribuição granulométrica sobre a secagem de concretos refratários. sv - sem vibração.

[Figure 6: Influence of (a) water content and (b) particle size distribution on the drying behavior of refractory castables. sv - without vibration].

Os resultados indicam também que a ausência de vibração pode acarretar acúmulo de água no corpo, aumentando a permeabilidade pela formação de regiões com adensamento não uniforme de partículas. Isto indica que a aplicação de vibração é aconselhável, ainda que os concretos apresentem comportamento auto-escoante $(\mathrm{q}=$ $0,26 \mathrm{com} 16 \%$ vol de água). A variabilidade apresentada pelas constantes de permeabilidade $k_{1}$ e $k_{2}$ dos concretos não-vibrados deve também ser encarada como problemática para a previsão de propriedades de transporte (secagem e infiltração), assim como para a garantia de um produto homogêneo. A escolha do concreto ideal deve indicar para aquele que possua a maior velocidade de secagem (significando economia de tempo e energia durante essa etapa, além de evitar riscos de explosão), porém com baixa permeabilidade após a queima (significando baixa susceptibilidade à infiltração de metais ou gases corrosivos). Uma vez que o mecanismo predominante de aumento de permeabilidade está relacionado à quantidade de interfaces matriz-agregado e não ao teor de água adicionada, a otimização da permeabilidade dos concretos multifuncionais deve estar fundamentada na sua distribuição granulométrica. A avaliação de outras propriedades, como resistência mecânica e choque térmico, deve também ser considerada na escolha da melhor composição. 


\section{CONCLUSÕES}

O objetivo deste trabalho foi verificar como o teor de água e a distribuição granulométrica podem afetar as propriedades fluidodinâmicas de concretos refratários multifuncionais. Os resultados indicaram que o principal mecanismo de aumento de permeabilidade em concretos a verde é o efeito de parede entre matriz e agregado, gerando poros menos tortuosos e mais permeáveis. A ausência de vibração durante a conformação resultou em concretos menos homogêneos, com maior acúmulo de água na estrutura e maior permeabilidade residual (após secagem). Não foi verificada variação significativa da porosidade aparente com a variação do coeficiente de Andreasen (q), mas apenas com o aumento no teor de água, confirmando que a morfologia e não a quantidade dos poros é responsável pela intensificação do transporte interno de fluidos. A secagem dos concretos foi facilitada pelo aumento da fração de agregados e com o teor de água. Os resultados indicam que a otimização da permeabilidade dos concretos refratários deve ser fundamentada em sua distribuição granulométrica, como forma de garantir um produto homogêneo e de secagem rápida.

\section{AGRADECIMENTOS}

Os autores agradecem a FAPESP, CNPq, CAPES e Alcoa Alumínio S.A. pelo apoio na realização deste trabalho.

\section{REFERÊNCIAS}

[1] J. Mosser, G. Karhut, Proceedings of the Unified International Technical Conference on Refractories-UNITECR' 99, Berlin-Germany (1999) 25-30.

[2] A. R. Studart, R. G. Pileggi, V. C. Pandolfelli, $44^{\circ}$ Congresso Brasileiro de Cerâmica, Águas de S. Pedro, SP, (2000) 12.

[3] M. D. M. Innocentini, A. R. F. Pardo, V. C. Pandolfelli, Proceedings of the Unified International Technical Conference on Refractories UNITECR' 99, Berlin - Germany (1999) 93-96.

[4] M. D. M. Innocentini; A. R. F. Pardo, V. R. Salvini, V. C. Pandolfelli, Am. Ceram. Soc. Bull. 78, 11 (1999) 64-68.

[5] M. D. M. Innocentini, V. C. Pandolfelli, Cerâmica45, 292/293 (1999) 61-67.

[6] K. L. Scrivener, K. M. Nemati, Cem. Conc. Res. 26, 1 (1996) 35-40.

(Rec. 09/09/00, Ac. 10/11/00) 